\title{
How to decarbonize the transport sector?
}

\author{
Bob van der Zwaan ${ }^{\text {a,b,c,*, Ilkka Keppo }}{ }^{\text {a,d }}$, Filip Johnsson ${ }^{\mathrm{e}}$ \\ a Policy Studies Department, Energy research Center of the Netherlands, Amsterdam, the Netherlands \\ ${ }^{\mathrm{b}}$ Lenfest Center for Sustainable Energy, the Earth Institute, Columbia University, New York, USA \\ c School of Advanced International Studies, Johns Hopkins University, Bologna, Italy \\ ${ }^{\mathrm{d}}$ Energy Institute, University College London, London, United Kingdom \\ e Department of Energy and Environment, Chalmers University of Technology, Göteborg, Sweden
}

\section{H I G H L I G H T S}

- In our approach transportation decarbonizes later than e.g. power production.

- Hydrogen becomes the dominant transport fuel during the 2nd half of the century.

- Electricity dominates if electric car costs go down by more than an extra $40 \%$.

- This holds even if $\mathrm{H}_{2}$ infrastructure proves much more costly than assumed today.

\section{A R T I C L E I N F O}

\section{Article history:}

Received 7 March 2012

Accepted 30 May 2013

Available online 10 July 2013

\section{Keywords:}

Transportation and Climate change

$\mathrm{CO}_{2}$ emissions abatement

Hydrogen versus electricity

\begin{abstract}
A B S T R A C T
This article investigates possible evolution pathways for the transport sector during the 21st century globally and in Europe, under a climate change control scenario. We attempt to shed light on the question how the transport sector should best be decarbonized. We perform our study with the global bottom-up energy systems model TIAM-ECN, a version of the TIAM model that is broadly used for the purpose of developing energy technology and climate policy scenarios, which we adapted for analyzing in particular the transport sector. Given the global aggregated perspective of TIAM-ECN, that in its current version yields at every point in time a single $\mathrm{CO}_{2}$ price for different forms of energy use across geographic regions and economic sectors, it generates a decarbonization process that for the transport sector occurs later in time than for the power sector. This merely reflects that emission reductions are generally cheaper for electricity production than for transportation, and that it is thus cost-minimizing to spend limited financial resources available for $\mathrm{CO}_{2}$ emissions abatement in the power sector first. In our scenarios the use of hydrogen in internal combustion engines and fuel cells, rather than electricity as energy carrier and batteries to store it, gradually becomes the dominant transport technology. This outcome is in agreement with some recent publications but is at loggerheads with the current popularity of the electric car. Based on sensitivity analysis we conclude that even if the establishment of a hydrogen infrastructure proves about an order of magnitude more costly than modeled in our base case, electricity based transportation only broadly emerges if simultaneously also the costs of electric cars go down by at least $40 \%$ with respect to our reference costs. One of the explanations for why the electric car is today, by e.g. entrepreneurs, often considered the supposed winner amongst multiple future transportation options is that the decision horizon of many analysts is no more than a few decades, instead of a full century. Electric cars fit better the current infrastructure than hydrogen fueled vehicles, so that from a short time perspective (covering the next decade or two) investments are not optimally spent by establishing an extensive hydrogen distribution network. Hence the path-dependency created by the present existence of a vast power transmission and distribution network can make electricity the most efficient choice for transportation, but only if the time frame considered is short. Electric transportation generally proves the more expensive alternative in our long-term perspective, except when electric car costs are assumed to drop substantially.
\end{abstract}

(c) 2013 Elsevier Ltd. All rights reserved.

\footnotetext{
* Corresponding author at: Energy research Center of the Netherlands, Policy Studies Department, Radarweg 60, 1043 NT Amsterdam, the Netherlands. Tel.: +31224564442.

E-mail address: vanderzwaan@ecn.nl (B. van der Zwaan).
} 


\section{Introduction}

This article investigates possible evolution pathways for the transport sector, globally and in Europe, under a climate change control scenario. The European Commission (EC) recently presented a roadmap for possible action up to 2050, which could enable the European Union (EU) to deliver greenhouse gas (GHG) emission reductions in line with the overall economy-wide target, aggregated over all main sectors, of $80-95 \%$ that the EC has defined (EC, 2011a). This roadmap argues that electricity will play a central role in a future low-carbon economy, since by 2050 the EC can almost entirely eliminate $\mathrm{CO}_{2}$ emissions in the power sector, notably (but not only) through the large-scale use of renewables. Electricity also offers the prospect of partially replacing fossil fuels used in transportation, so that in this sector, according to the EC, at least 60\% GHG emission reductions can be achieved in 2050 with respect to 1990 (EC, 2011b). It is broadly recognized that new technologies for vehicles and traffic management will be key to lower transport emissions in the EU as in the rest of the world. A gradual transition towards a large-scale penetration of cleaner vehicles in all transport modes would probably include hybrid engine technologies in the short term and plug-in hybrids and electric vehicles powered by batteries or fuel cells at a later stage. This subject is given ample attention by policy makers as well as in the current scientific literature (see e.g. Johnsson, 2011a).

We perform our study with the bottom-up linear programming model TIAM-ECN, a version of the well-known and broadly publicized TIAM model (see Loulou and Labriet, 2008; Loulou, 2008, and references therein), adapted at the Energy research Centre of the Netherlands (ECN) and used like other TIAM models for energy and climate policy analysis. TIAM is member of the widely established TIMES (The Integrated MARKAL-EFOM System) family of models (on which TIAM's name is based: TIMES Integrated Assessment Model), successor to the MARKAL (Market Allocation) model that has served the energy scenario and integrated assessment community for several decades. The main question that we attempt to answer in this paper is how and the extent to which to decarbonize the transport sector in a global optimization regime. In particular, we investigate the technological means with which this sector may best be cleared from emissions of $\mathrm{CO}_{2}$. Unless air capture of $\mathrm{CO}_{2}$ from the atmosphere becomes a feasible and affordable technology (Lackner et al., 2012), an essentially complete decarbonization of the transport sector is ultimately necessary if stringent climate change constraints are to be met. For this paper we have chosen not to analyze policy targets other than related to climate change, even while other important measures could contribute to fundamentally altering the nature of the transport sector, including policy instruments directed at reducing air pollution or stimulating energy independence. These topics though fall beyond the scope of this article, which focuses on global climate change only. For other recent studies on GHG emission reduction strategies (including for transportation) performed with a TIMES model, see for example Yeh and McCollum (2011) and McCollum et al. (2012).

Within the transport sector this paper investigates predominantly the development of personal vehicle technology, since cars currently constitute the main focus of the transport policy debate and their aggregated global GHG emissions are higher than for the other transport sub-sectors. Among issues such as driving range and fueling time, two factors strike us as particularly important determinants for which car technologies will become long-term players in the personal transport sector: investments cost and operational cost. The investment cost, or purchase price, of cars heavily influences consumer choice. Energy use per distance traveled (i.e. their efficiency or mileage) has significant effect on their operational cost, and hence on their attractiveness and the overall car diffusion potential. Cost and efficiency values for cars today affect their chance for near-term success, and similarly crucial is how these quantities evolve over the long term, i.e. over the next several decades.

We opted for employing TIAM-ECN as preferred methodology to investigate this subject matter, precisely since this bottom-up integrated assessment model of energy-climate-economy interactions captures well both aspects of costs and efficiency, and their potential for future improvement, for a large set of different feasible technologies and innovations in the transport sector. In addition, TIAM-ECN permits simulating essentially all other parts of the global energy economy, so that the evolution of the transport sector can also be inspected in relation to that of (often correlated) other sectors. Furthermore, its global geographical disaggregation allows studying regional energy systems as parts of the global energy system.

Our approach allows for addressing several other subsidiary and related issues. In principle many complementary subjects can be inspected, including, for example, (1) the linkages of an expansion or transformation of the transport sector to the development of other energy-intensive sectors (such as those producing the required (petroleum or other) fuels) as well as the repercussions of a decarbonization of the transport sector for industry and power generation (cf. EC, 2011a), and (2) the relation between a decarbonizing transport sector and the prospects for the deployment of a series of specific technologies (such as batteries and fuel cells, used in cars, or $\mathrm{CO}_{2}$ capture and storage (CCS), needed in several scenarios to generate climate-friendly energy carriers - cf. e.g. Burke and Zhao, 2012; Schoots et al., 2010; Johnsson, 2011b). Section 2 of this paper presents the details of our simulation and optimization assumptions in the TIAM-ECN model. Section 3 describes the main results in our base scenario, particularly in terms of $\mathrm{CO}_{2}$ emission profiles, car technology diffusion and transport fuel price developments. In Section 4 we report and discuss the results of our alternative, but equally plausible, scenarios, which we analyzed to test our findings and inspect their robustness under changes in our parameter assumptions; we here also compare our outcomes with those reported in the recent literature on this subject matter (see e.g. Barreto et al., 2003; Göransson et al., 2010; Grahn, 2009; Hedenus et al., 2010; McKinsey, 2010). In Section 5 we summarize our major conclusions, as well as hint at a couple of subjects that invite further research, by us and the community of transportation analysts at large.

\section{Methodology: TIAM-ECN}

Many features of the technology-rich energy systems engineering model TIAM-ECN, especially regarding the transport sector, have been extensively described in Rösler et al. (2011). Like the original TIAM it is a linear optimization model simulating the development of the global energy system from resource extraction to final energy use over a period of about 100 years. Its regional disaggregation separates the world in 15 geographical areas, including Eastern and Western Europe. Europe (East plus West) is part of our focus in this paper and is defined here as excluding Turkey and the countries formerly belonging to the Soviet Union. TIAM-ECN keeps all the main characteristics and many of the details of the original TIAM, but includes a series of modifications, elaborations and improvements for particularly transportation. Most of the changes concern updated input values for many technical and economic parameters, and the introduction of growth and decline constraints for various energy resources, 
technologies and end-use applications. Other changes involve just simplifications, such as more aggregated sectoral and technological specification for those parts of the original TIAM model that we considered to be too detailed in perspective of its global orientation and the purposes of this article.

The objective function of TIAM-ECN consists of the total aggregated discounted costs over the full time horizon, summed across all regions. Running scenarios with TIAM means minimizing this objective function. The main cost components included in this minimization program are the investment costs and fixed and variable operation and maintenance costs. Smaller terms like decommissioning costs are also included. Since the model is based on a partial equilibrium approach, with demands for end-use energy services responding to changes in end-use prices through own-price elasticities, the costs and savings implied by demand variations are also accounted for. The extensive database associated with TIAM includes hundreds of technologies for a broad set of different sectors. Fuel prices are determined endogenously, as shadow prices, and are therefore not an input to but a result of model runs. For a general description of the reference energy system of TIAM, see Syri et al. (2008) and Loulou and Labriet (2008).

In addition to energy flows and conversion technologies, many environmental variables such as atmospheric emissions from energy processes are modeled. TIAM-ECN includes in principle all sources of the three main GHGs, i.e. $\mathrm{CO}_{2}, \mathrm{CH}_{4}$ and $\mathrm{N}_{2} \mathrm{O}$, but currently excludes emissions of other types of pollutants such as $\mathrm{SO}_{\mathrm{x}}$ and $\mathrm{NO}_{\mathrm{x}}$. Energy related GHGs are modeled endogenously, whereas non-energy related GHGs are included through exogenously given emission paths. The latter are based on assumptions concerning their underlying drivers. Mitigation technologies are available for some of these non-energy related GHG emissions (such as the use of different types of fertilizers in agriculture). An endogenous 3-reservoir climate change module simulates $\mathrm{CO}_{2}$ dispersion in the atmosphere plus upper and lower parts of the ocean, while a 1-reservoir approach is used for $\mathrm{CH}_{4}$ and $\mathrm{N}_{2} \mathrm{O}$ diffusion in the atmosphere (see Syri et al., 2008, for a detailed description). Emissions of pollutants that affect the global climate but are not directly included in TIAM-ECN (such as CFCs and non-Kyoto gases) are represented through an exogenous forcing component in the climate change module. In Keppo and van der Zwaan (2012), reporting a stochastic analysis with TIAM-ECN of the impact of uncertainty in climate change targets on optimal long-term GHG emissions abatement, we give further account of our assumptions regarding the simulation of the climate system and environmental features of the energy system.

A large number of GHG mitigation options are modeled for the energy sector. Based on the costs assumed for all (mitigating and non-mitigating) energy technologies, TIAM-ECN minimizes the overall energy system cost across the 21st century. The main clusters of mitigation alternatives are: (1) reductions in the carbon intensity of fuels (such as a switch from coal to gas, or from fossil fuels to renewables or nuclear energy), (2) technologies for energy consumption reduction (including more efficient conversion techniques on the supply side and demand reductions through various means at the end-use level), and (3) add-on technologies (such as $\mathrm{CCS}$ or $\mathrm{CH}_{4}$ emission reduction opportunities in oil, gas and coal production). Scores of different specific possibilities are implementable within each of these three main climate change mitigation categories, owing to the detailed simulation of the energy system in TIAM-ECN. As $\mathrm{CO}_{2}$ emission constraints are implemented, the energy resources and technologies with low carbon content become more competitive, as do options that require less fuel to provide the same energy service (and therefore in relative terms generate lower emission levels). A climate constraint
Table 1

Key assumptions concerning selected CCS options modeled in TIAM-ECN. Data sources reported in Keppo and van der Zwaan (2012) and Rösler et al. (2011).

\begin{tabular}{lllll}
\hline $\begin{array}{l}\mathbf{C O}_{2} \text { removal } \\
\text { technology }\end{array}$ & $\begin{array}{l}\text { Efficiency } \\
(\%)\end{array}$ & $\begin{array}{l}\text { Capture } \\
\text { rate }(\%)\end{array}$ & $\begin{array}{l}\text { Investment cost } \\
(\mathbf{U S S}(\mathbf{2 0 0 5}) / \mathbf{k W})\end{array}$ & $\begin{array}{l}\text { Annual O\&M } \\
(\mathbf{U S S} \mathbf{( 2 0 0 5}) / \mathbf{k W})\end{array}$ \\
\hline IGCC and PC & $44-48$ & 86 & $1980-2090$ & $65-68$ \\
NGCC & $55-57$ & 88 & $880-1050$ & $29-34$ \\
SOFC & $47-58$ & 90 & $1760-2420$ & $58-79$ \\
H $_{2}$ production & $62-80$ & 85 & $430-1250$ & $16-49$ \\
\hline
\end{tabular}

N.B. IGCC: Integrated gasification combined cycle; PC: Pulverized coal; NGCC: Natural gas combined cycle; SOFC: Solid oxide fuel cell; O\&M: Operation and maintenance.

increases the price of energy services, which leads to a lower overall energy services demand.

TIAM-ECN also simulates the finiteness of resource potentials for most low-carbon energy carriers and includes assumptions regarding the range of available efficiency improvements. These features may limit the use of $\mathrm{CO}_{2}$ abatement options. Climate change mitigation options may also be bounded by their baseline use: if a low-carbon technology is assumed to have a large potential, but this potential is almost completely used already in the business-as-usual scenario, then the scope for GHG mitigation for this technology is low. CCS technologies are modeled for the power sector, for synthetic fuel production (including $\mathrm{H}_{2}$ generation from coal and natural gas, and methanol and Fischer-Tropsch liquids from coal) and (without much detail and up to a maximum) upstream fossil fuel supply processes; their assumed cost and efficiency values determine their role in scenario runs. Largescale CCS deployment in real life depends on many additional factors other than costs and efficiency, including e.g. the institutional and regulatory feasibility of building an extensive $\mathrm{CO}_{2}$ pipeline infrastructure (see e.g. van der Zwaan et al., 2011), and public acceptance issues related to possible safety and environmental impacts of CCS; these are important aspects that TIAM-ECN cannot account for. Although much remains to be understood concerning the long-term integrity of geological $\mathrm{CO}_{2}$ storage formations (Gerlagh and van der Zwaan, 2006, 2012), TIAM-ECN accounts for a large number of storage options for the captured $\mathrm{CO}_{2}$.

Table 1 summarizes the ranges of our main CCS technology assumptions in TIAM-ECN. An extensive number of combinations are simulated between $\mathrm{CO}_{2}$ capture technologies and coal and natural gas based power plants and hydrogen production facilities. CCS as applied to the combustion of biomass or biofuels is not included in the version of TIAM-ECN that we used for this paper (but we do so in Rösler et al., 2013). This technology offers in principle a promising possibility for realizing negative GHG emissions, which may become essential to achieve a stringent climate change control constraint such as one in which the global average atmospheric temperature increase is limited to $2{ }^{\circ} \mathrm{C}$. It remains to be seen, however, to what extent biomass plus CCS technology can be applied in practice on a large scale, given possible logistical and spatial constraints, negative impacts in terms of biodiversity and food supply, as well as corrosion problems that need to be overcome when combining the combustion of biomass with high temperature processes in order to reach high efficiencies (similar arguments may hold for hydrogen production as well). If this technology becomes commercially feasible, or another option by which $\mathrm{CO}_{2}$ can be removed from the atmosphere, such as 'air capture', it could offer increased flexibility for reducing emissions rapidly. For more about how $\mathrm{CO}_{2}$ capture technologies and storage potentials are simulated, as well as the uncertainty ranges we assume herein, see Keppo and van der Zwaan, (2012) and Rösler et al. (2011). 
Table 2 lists for the 12 car types modeled in TIAM-ECN their assumed cost per vehicle, in US\$(2005), and efficiency, in $\mathrm{MJ} / \mathrm{km}$, both today (2010) and in the mid-term of our investigated timeframe (2050). Of these simulated car technologies, six are assumed not to decrease further in costs even while some of them still improve in terms of their technical performance: (advanced) diesel cars, (advanced) gasoline cars, liquid petroleum gas (LPG) cars and ethanol cars (see Rösler et al., 2011, for more details). Among these, three options are supposed to continue to evolve through efficiency improvements, since they have entered the market at a later stage than the other more established 3: advanced diesel and gasoline cars (including e.g. the currently deployed generation of hybrid cars) and cars running on ethanol. We have explicitly modeled advanced diesel and gasoline cars because we believe that there is still sizeable progress realizable in traditional cars running on current fuels, even without the introduction of substantial innovations (such as vehicle weight reductions). Hence we assume that the average fuel consumption for most relatively common car types (except those fueled by LPG) continues to decrease during future decades. The remaining six car types listed in Table 2 are assumed to be subject to simultaneous cost and efficiency improvements: cars running on natural gas, electric cars, two types of plug-in hybrids (diesel and gasoline based) and two types of hybrids running on hydrogen (with an internal combustion engine (ICE) or fuel cell (FC)). For electric cars, for example, we assume that investment costs reduce by about

Table 2

Reference assumptions for the car technology types simulated in TIAM-ECN. Data collected from Concawe (2008), Gül (2008), Uyterlinde et al. (2005) and IEA (2009). See Rösler et al. (2011) for more details.

\begin{tabular}{|c|c|c|c|c|}
\hline \multirow[t]{2}{*}{ Car } & $\begin{array}{l}\text { Investment } \\
\text { cost }\end{array}$ & $\begin{array}{l}\text { Investment } \\
\text { cost }\end{array}$ & Efficiency & Efficiency \\
\hline & $\begin{array}{l}2010 \\
\text { USS } \\
(2005 / \text { vehicle })\end{array}$ & $\begin{array}{l}2050 \\
\text { USS } \\
(2005 / \text { vehicle })\end{array}$ & $\begin{array}{l}2010 \\
M J / k m\end{array}$ & $\begin{array}{l}2050 \\
\mathrm{MJ} / \mathrm{km}\end{array}$ \\
\hline Diesel & 20780 & 20780 & 2.20 & 2.20 \\
\hline Advanced diesel & 21500 & 21500 & 2.10 & 1.70 \\
\hline Gasoline & 19720 & 19720 & 2.60 & 2.60 \\
\hline Advanced gasoline & 20500 & 20500 & 2.30 & 1.90 \\
\hline LPG & 21170 & 21170 & 2.30 & 2.30 \\
\hline Ethanol & 22550 & 22550 & 2.30 & 1.90 \\
\hline Natural gas & 22010 & 21500 & 2.30 & 1.90 \\
\hline Electric & 39640 & 31940 & 0.71 & 0.65 \\
\hline Plug-in hybrid diesel & 29070 & 26030 & 1.55 & 1.15 \\
\hline $\begin{array}{l}\text { Plug-in hybrid } \\
\text { gasoline }\end{array}$ & 27570 & 25030 & 1.60 & 1.20 \\
\hline Hydrogen ICE hybrid & 26940 & 25300 & 1.80 & 1.30 \\
\hline Hydrogen FC hybrid ${ }^{\mathrm{a}}$ & 33850 & 26300 & 1.10 & 0.95 \\
\hline
\end{tabular}

N.B. ICE: Internal combustion engine; LPG: Liquefied petroleum gas.

${ }^{a}$ For the hydrogen fuel cell (FC) car the 2010 figures actually refer to 2020, which is the first year this car type is available in our model.
$20 \%$ over four decades primarily as a result of assumed battery cost decreases.

Especially (but not only) for those car types that so far have not yet been produced on a large scale, the figures listed in Table 2 are assumptions, based on various specialized sources such as IEA (2009). These numbers have been introduced in TIAM-ECN in our latest modeling update. Particularly those referring to the mid-term future (2050) may turn out different in reality, but they are in agreement with the ranges suggested in the literature today and are compatible, for instance, with the shorter term data presented in Sperling and Lutsey (2009) and EPA (2010). Our cost reduction assumptions for hydrogen FC hybrid cars (20\% between today and 2050) are consistent with recent studies that report steep learning curves, with rates over $20 \%$ per doubling of manufactured capacity, for various types of fuel cells (as demonstrated by Schoots et al., 2010; Rivera-Tinoco et al., 2012). To our knowledge no such learning phenomena have been observed for batteries, although learning rate values of $10 \%$ have been claimed (IEA-ETP, 2012), which back our assumptions for the costs of electric cars in 2050. Supposing lower long-term costs for fuel cell cars than for electric vehicles seems justified on the grounds that the former are cheaper today and are clearly subject to pronounced learning-by-doing.

We also make assumptions with regards to other car technology characteristics. We set the annual average distance driven per vehicle at $12,000 \mathrm{~km}$, and the lifetime of a car for all types at 12.5 years (by which we abstract in principle from the possibility that lifetimes may vary across car technologies, and that different types may ultimately serve different (niche) markets, travel purposes and/or driving ranges). We assume that the interest rate for levelizing investment costs (i.e. purchase prices) is $15-30 \%$-the specific value depends on the region considered, but we suppose it is the same for all cars within a given region. Costs are also regiondependent: the figures for Western Europe are 10\% higher than the reference values listed in Table 2; the US figures match these reference costs, while for China and India costs are 10\% below these numbers. For plug-in hybrids we assume that about $50 \%$ of car usage takes place using the electromotor, while for the remainder the lower efficiency ICE is used, fueled by diesel or gasoline (see e.g. IEA, 2009). The list of depicted car types is not complete - combinatorics such as plug-in hydrogen hybrid cars (equipped with an ICE or FC) are imaginable - but for studying the generic dynamics between the main technology varieties that are possible, or that are likely to be deployed during the 21st century, this diversity is sufficient. In case hydrogen becomes a widely used fuel, an infrastructure is needed for its transportation, which we model stylistically by assuming hydrogen transmission and distribution costs that amount (in the base case) to $2 \$ / G J$. For our long-term scope covering the entire 21 st century, the magnitude of infrastructure costs poses a more limited hurdle than when the horizon of analysis is only a couple of decades: in a time span of 100 years the difference in costs between existing and new infrastructure (as for electricity versus hydrogen) matters less.
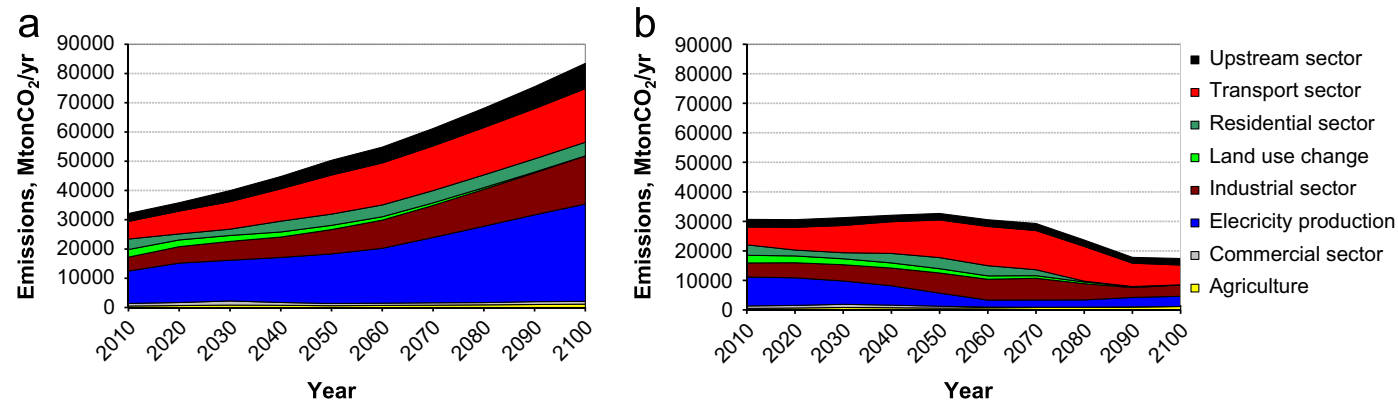

Fig. 1. Global $\mathrm{CO}_{2}$ emissions per sector: baseline (left panel) and under a $4.0 \mathrm{~W} / \mathrm{m}^{2}$ climate constraint (right panel). 

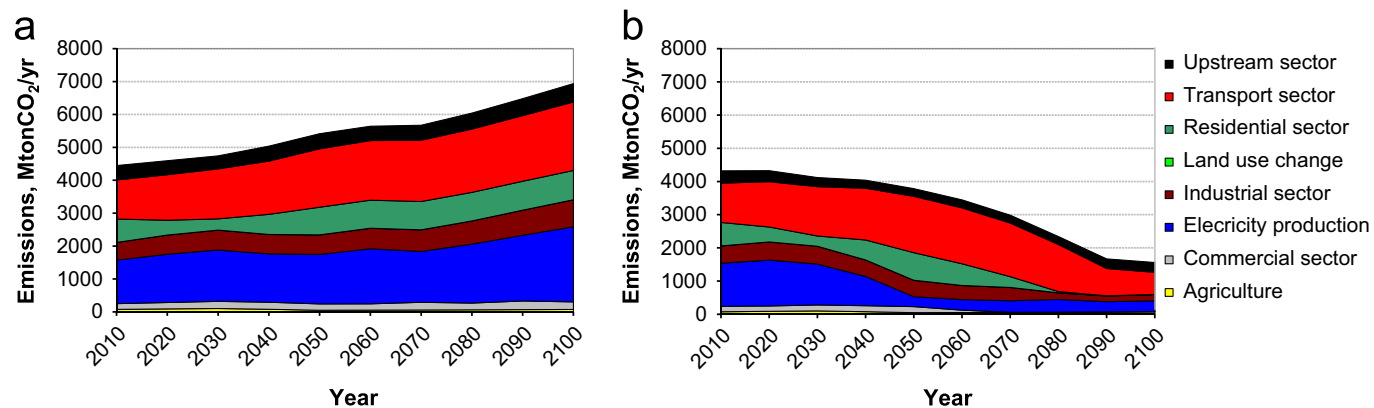

Fig. 2. $\mathrm{CO}_{2}$ emissions in Europe per sector: baseline (left panel) and under a $4.0 \mathrm{~W} / \mathrm{m}^{2}$ climate constraint (right panel).

\section{Simulation results base scenario}

A climate change constraint is implemented in TIAM-ECN through the imposition of an upper limit to the additional atmospheric radiative forcing (in $\mathrm{W} / \mathrm{m}^{2}$ ) induced by GHG emissions. Fig. 1 depicts two global $\mathrm{CO}_{2}$ emission paths until 2100 obtained with TIAM-ECN, under a baseline scenario (left panel) and in case a $4.0 \mathrm{~W} / \mathrm{m}^{2}$ forcing constraint is imposed (right panel). ${ }^{1}$ The baseline scenario corresponds to what most specialists would agree constitutes, within the range of published scenarios, a middle-of-the-road reflection of how emissions of this GHG could evolve under business-as-usual assumptions with regards to population increase, economic growth and fossil energy use (see e.g. GEA, 2012). The other scenario (Fig. 1, right panel), realized through targeted climate policy, results from the long-term requirement that additional atmospheric radiative forcing does not exceed $4.0 \mathrm{~W} / \mathrm{m}^{2}$. It proves that this scenario corresponds until the middle of the century (but not afterwards) to keeping $\mathrm{CO}_{2}$ emissions at status quo, that is, to realizing a 'stabilization triangle' worth of $\mathrm{CO}_{2}$ emission reductions in the terminology of Pacala and Socolow (2004). Of course, in the longer run, in order to reach climate stabilization, emissions need to be reduced significantly. Emission reductions need to be even deeper than in this climate change control scenario if we are to reach a $2{ }^{\circ} \mathrm{C}$ temperature target.

In our climate change control scenario large $\mathrm{CO}_{2}$ emission abatement efforts start almost immediately with respect to the business-as-usual case. While these are insufficient to achieve a maximum average temperature increase of $2{ }^{\circ} \mathrm{C}$, and thus fall short of reaching currently expressed climate goals, we chose a global mitigation regime that is more realistic of being actually established. While the current policy discussion centers around the $2{ }^{\circ} \mathrm{C}$ target, so that consequently many modeling studies use this value, many publications point out that it is unlikely that reaching this target is feasible, in light of the current emission trends and the international agreements that would be required to stabilize climate change (see e.g. Anderson and Bows, 2008; Victor, 2009). It is also clear that the current 'Copenhagen' pledges are not consistent with the $2{ }^{\circ} \mathrm{C}$ target (Höhne et al., 2012). The IPCC 4th assessment report (IPCC, 2007, p.104) summarized the climate impacts of 177 energy systems scenarios, of which only six were consistent with a $2.0-2.4{ }^{\circ} \mathrm{C}$ temperature increase. Hence our maximum climate change target of $4.0 \mathrm{~W} / \mathrm{m}^{2}$ is a compromise between the stated goals of policy makers and what the current state of climate negotiations and various trends suggest might be within reach.

${ }^{1}$ Using the IPPC (2007) terminology, this (total aggregate) forcing target would give a likely range of about $2.5-4.0^{\circ} \mathrm{C}$ warming at equilibrium (reached well after 2100), if the probability density function developed by Forest et al. (2002), under uniform first priors, was used for the climate sensitivity.
As can be seen from Fig. 1, all economic sectors must contribute to climate mitigation efforts, but power generation is during the first half of the century the most important sector suitable for cost-efficient decarbonization, e.g. through the use of CCS, nuclear energy and renewables (cf. O'Neill et al., 2010). The transport sector remains relatively unaffected before 2050 , but subsequently is subjected to considerable change with respect to the baseline scenario. The inertia during half a century observed in the transport sector hinges directly on our overall energy systems approach and unique $\mathrm{CO}_{2}$ price at each point in time across all economic sectors. While with TIAM-ECN this inertia proves the optimal cross-sectoral outcome, in reality firms in the automotive sector invest much more and earlier in technological innovation and climate change mitigation than transpires from our methodology, and car owners may be willing to pay more per unit of $\mathrm{CO}_{2}$ abatement in transportation than they would in other sectors such as power production. To properly study such (timing) effects, models dedicated to the transport sector should be employed (cf. the 'reality check' study on timing and investments for the introduction of innovative light-duty vehicles by Plotkin et al., 2013).

Fig. 2 shows $\mathrm{CO}_{2}$ emission pathways under the same scenarios as depicted in Fig. 1, but for (East plus West) Europe only: business-as-usual (left panel) and under the $4.0 \mathrm{~W} / \mathrm{m}^{2}$ climate forcing constraint (right panel). As can be observed, European $\mathrm{CO}_{2}$ emission (reduction) trends are rather similar to the global patterns, but display a few marked differences. In the baseline scenario, emissions of $\mathrm{CO}_{2}$ increase less rapidly in Europe than globally. Like in the global case and explained in association with Fig. 1, the decarbonization of the European transport sector lags behind that of electricity generation, which we do not necessarily consider commensurate to what is likely to happen in real life. In Europe, $\mathrm{CO}_{2}$ emission reductions in absolute terms start today in the climate change control scenario, while these only take off around the middle of the century at the global level. The share of European $\mathrm{CO}_{2}$ emissions to the global figure decreases rather independently of whether in the baseline or climate change control scenario: the European contribution to total global $\mathrm{CO}_{2}$ emissions amounts to about 15\% in 2010 and decreases in each case to below $10 \%$ by 2100 .

Fig. 3 shows the corresponding results for the European transport sector only, for five major categories: buses, cars, trucks, planes and a class of remaining modes including ships and trains. By disaggregating transport sector emissions, Fig. 3 shows that (1) significant $\mathrm{CO}_{2}$ emission increases are modeled for passenger cars in the baseline, given a high expected economic growth in Eastern Europe and a still progressing level of private car ownership in Western Europe (left panel), and that (2) little climate change mitigation activity (relative to the baseline) takes place in the five sub-sectors before 2050 under the $4.0 \mathrm{~W} / \mathrm{m}^{2}$ climate constraint (see right panel). The latter outcome, however, reveals the nature of our type of global aggregated multi-sector model, which would not necessarily be 

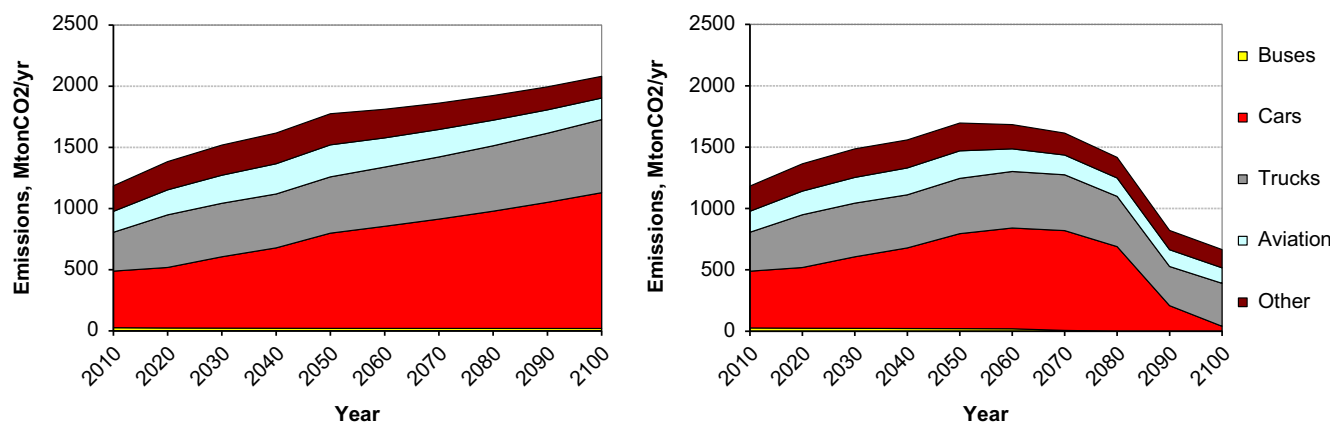

Fig. 3. $\mathrm{CO}_{2}$ emissions in the European transport sector: baseline (left panel) and under a $4.0 \mathrm{~W} / \mathrm{m}^{2}$ climate constraint (right panel).
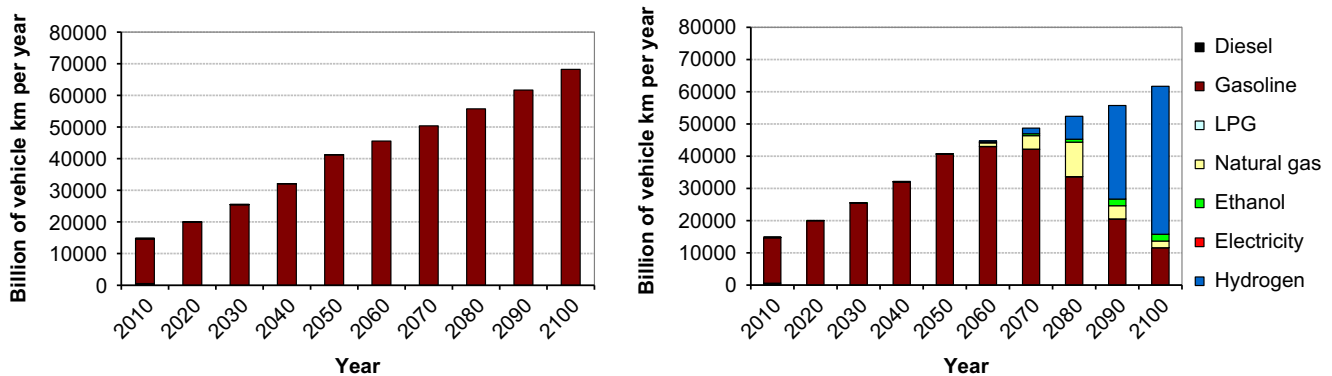

Fig. 4. Global annual car usage, in billions of vehicle kilometers driven per year: baseline (left panel) and under a $4.0 \mathrm{~W} / \mathrm{m}^{2}$ climate constraint (right panel).

generated by a one-sector model dedicated to transportation only. While (from around the middle of the century) emissions from all transport categories go down, the class of car technologies appears the most apt to contribute to climate change mitigation in this sector, as shown by the rapid decline in $\mathrm{CO}_{2}$ emissions from this category during the last decades of the century. Since cars constitute an even more widely employed mode of transportation in 2100 than today (in Europe as well as globally), this result implies that the carbon intensity of cars has dropped to a level close to zero by then.

As can be seen from Fig. 3, the category of buses contributes little to overall emission levels. Heavy duty transportation (through trucks), aviation (involving both cargo and passenger planes) and a mix of other transport modes (among which cargo and passenger ships) decrease their $\mathrm{CO}_{2}$ emissions, even while the demand for these modes is assumed to grow during the century. Despite this reduction in emission intensity and absolute emissions, however, they still remain significant emitters by 2100 . This finding is in agreement with the claim that trucks, planes and ships are less easily transformable to zero-emitting transport means than cars or light duty vehicles (Schäfer et al., 2009). Price-induced shifts between the five transport categories may become responsible for changes in the overall $\mathrm{CO}_{2}$ emission profile of the transport sector. The dynamics behind such systemic adaptations of (modal switches in) the transport sector, however, including for instance changes from the use of cars to buses or from planes to other means of public transport, are not included in our model, and can better be studied with models other than TIAM-ECN.

Because our main interest in this paper is transportation through cars, we show in Fig. 4 the evolution of the number of kilometers driven by vehicles around the globe every year (expressed in this unit since it is suitable to describe the market shares of different car types and fuels). In the business-as-usual scenario (left plot) car usage increases roughly linearly from around $15 \mathrm{Tkm} / \mathrm{yr}$ in 2010 to some $70 \mathrm{Tkm} / \mathrm{yr}$ in 2100, while gasoline remains by far the most predominant fuel for the rest of the century. Today, diesel (which in our model includes biodiesel, even while it proves to play only a marginal role in the majority of scenario runs) also plays a sizeable role as transportation fuel, especially in Europe (see also Fig. 5). Our vehicle purchase price assumptions (lower for gasoline than for diesel fueled cars), however, reduce the use of diesel to negligible levels in about a decade from now (we have not further studied the mutual dynamics between gasoline and diesel cars, as our focus is on climate change mitigation and the corresponding long-term fundamental changes necessary in the transport sector, plus TIAM$\mathrm{ECN}$ is inapt to analyze real-life short-term developments in the transport sector).

Fig. 4 also demonstrates (right plot) that no significant changes take place in this pattern until the middle of the century (with respect to the baseline) if the energy system is subjected to climate change control - as expected given our earlier findings for the transport sector - in terms of either the number of $\mathrm{km}$ driven or the main types of vehicle technology deployed. Only from around 2060 do we observe modest change in these two variables. This outcome is in agreement with the findings reported in the IEA Energy Technology Perspectives publication that presents a marginal abatement cost curve (MACC) for $\mathrm{CO}_{2}$ in which (after the implementation of savings and efficiencies) power production is the first sector to be subjected to drastic emission reductions, only followed by the transport sector when both electricity generation and industry have been largely decarbonized (IEA-ETP, 2010). But, as explained, we nuance the practical meaning of this result on the timing of $\mathrm{CO}_{2}$ abatement in the transport sector, as it is reflective of the way TIAM-ECN functions and does not necessarily represent the real-life timeframe by which substantial change in transportation could to take place under drastic climate change control action. Fig. 4 repeats what we derived from the $\mathrm{CO}_{2}$ emission patterns shown in Figs. 1 through 3: until around 2060 the vast majority of cars are evolutionary versions of conventional cars running on gasoline, while only afterwards are other technologies and fuels introduced. The new cars are mostly fueled with natural gas, ethanol and, especially, hydrogen. These options remain reserved for relatively small niche markets during about two decades. From around 2080 these more innovative energy carriers start to significantly contribute to fueling the global car park. By 

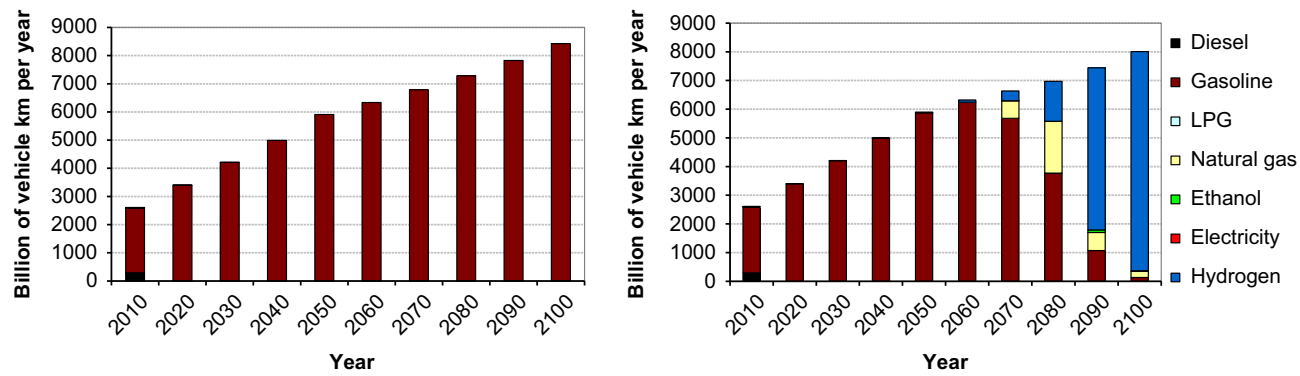

Fig. 5. European annual car usage, in billions of vehicle kilometers driven per year: baseline (left panel) and under a $4.0 \mathrm{~W} / \mathrm{m}^{2}$ climate constraint (right panel).
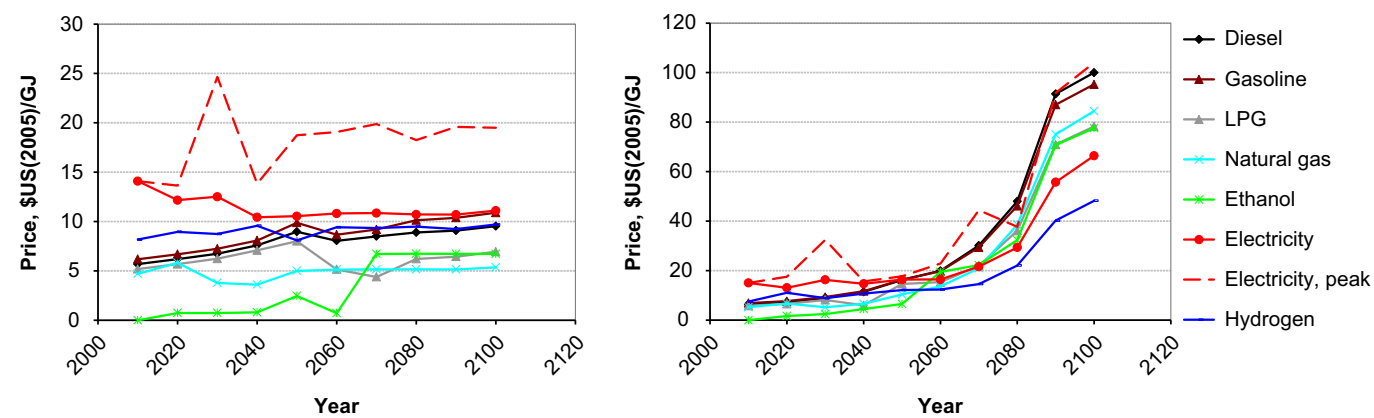

Fig. 6. Price of road transport fuels in Europe: baseline (left panel) and under a $4.0 \mathrm{~W} / \mathrm{m}^{2}$ climate constraint (right panel, includes the implied $\mathrm{CO}_{2}$ tax).

2100 hydrogen appears the main cost-efficient option for lowcarbon cars in the transport sector. This finding is quite contrary to what the current popular discourse around electric cars suggests, which we explain and inspect in the next section.

Although barely visible, Fig. 4 implies that hydrogen cars start appearing in small numbers already in 2040 and that it takes about 30 years until the market share reaches $5 \%$. During this period (and afterwards) the growth rate of the hydrogen car fleet never exceeds around 15\%/yr. This is a reasonable upper boundary, as we have encountered it in the car industry already (during the 20th century the global car fleet increased from around 8000 passenger cars in 1900 to some $700,000,000$ in 2000, implying an average annual growth rate of about $12 \% / \mathrm{yr}$ ) and have often seen higher rates in other sectors, including especially the energy sector (cf. the expansion of solar and wind power over the past decades with rates of around 30\%/yr). From 2070 to 2090 there is a rapid expansion of the hydrogen vehicle park (in absolute not in relative terms, since the annual growth rate drops substantially). This rapid increase is driven by strong climate regulation, which forces the transport sector to switch to low-carbon cars. Historical examples show that in such cases technologies can diffuse rapidly. For example, flue gas desulfurization (FGD) systems diffused fully in the US in about 25 years, with an approximate time constant of about 10 years (Taylor et al., 2005). This is fairly similar to what can be calculated for hydrogen cars from our results (around 8 years if we take the 2100 car transport demand as the saturation level, or about 12 years if we assume the saturation level to be $20 \%$ above the 2100 numbers). Nakicenovic (1986) reached similar conclusions for the diffusion of emission control technology for cars in the US in the 1970s and 1980s: the transition had a time constant of about 10 years, again roughly comparable to our figures. The transition required in our case would in some respects perhaps be more fundamental, and may therefore be considered optimistic, but does certainly not seem impossible (for a recent update of the literature on this subject, see Grübler, 2012).

Fig. 5 shows the corresponding model results for the European transport sector. The main deviation for the European case in comparison to (an otherwise similar development of) global car usage, is that hydrogen as a fuel penetrates to an even larger degree by the end of the century. In other words, Europe (along with Japan and the US, amongst others) is found to very modestly lead the innovation process in the car industry, while other regions (such as China and India) follow (a result that derives partly from the use of different interest rates for the purchase of cars in different regions). Qualitatively these graphs change little when all road transport modes (including e.g. trucks and buses) are analyzed, instead of cars only. The main difference is that some diesel as heavy duty transport fuel would be introduced, both in the baseline and in the scenario with climate change mitigation. Climate change control in our model proves to have only moderate effect on the number of cars used in any particular year this century, partly as a result of the potential of materializing fuel efficiencies and emission intensity reductions: in the baseline the number of cars used in Europe is simulated to increase from around 200 million in 2010 to 500 million in 2050 and 700 million in 2100 , while in the climate change control scenario the latter figure reduces by about 5\% (whereas the numbers for 2010 and 2050 are little affected). Globally the aggregated car park in the baseline scenario increases from around 1200 million vehicles in 2010 to 3400 million in 2050 and 5700 million in 2100; in the climate change control scenario the last figure reduces by approximately $10 \%$. The European share of total global car ownership reduces over time in both scenarios.

Fig. 6 shows the evolution of the price of road transport fuels in Europe until 2100, for both the baseline and climate change control scenarios. The graphs depict the shadow prices as calculated by TIAM-ECN, hence they are output of, and not input to, our model. In the climate change control scenario these include, and are strongly determined by, the carbon tax. This implies that in our model they do not directly correspond to market fuel prices. Rather, they constitute the value of having a particular fuel available. The shadow price can approach zero if fuel supply is not a constraining factor and other issues govern the (non-)use of the fuel under consideration. For example, if $\mathrm{H}_{2}$ was only usable in the transport 
sector, its value would be zero in the baseline. This is because even with zero fuel costs, the high investment costs of a $\mathrm{H}_{2}$ car would leave the model with more lucrative options for the transport sector. Similar issues can apply to other energy carriers, which explains for example the zero ethanol price in early decades.

One observes from the baseline in Fig. 6 that fuel prices, apart from the early decades, stay fairly close to each other, in the range of 5-10 \$/GJ. These translate into $0.18-0.35 \$ \mathrm{US} /$ liter of gasoline, and thus correspond to about 25-50 \$US/barrel of crude oil (that is, low in comparison to currently prevailing oil prices). We do not assume other policy measures applied to fuel services (such as taxes or subsidies) except for the tax implied by climate change control. Hence, fuel price results are based on optimality alone and do not reflect various existing national fuel policies. The only deviation from the price range of 5-10 \$/GJ is the price of peakload electricity, which can be explained by its non-base-load nature. The variation in the values observed for different fuels results mainly from the broad spectrum of available technology options that use a given fuel, some additional constraints, as well as the efficiency of fuel usage (typically higher for electricity than for hydrocarbon fuels). These facets in addition to fuel availability are reflected in the value of the shadow price. The cheapest fuels are natural gas, LPG and ethanol, whereas the more traditional fossil fuel prices lie close to each other, at around 10 \$US/GJ. Hydrogen tends to be somewhat cheaper than electricity, since hydrogen is mostly produced through mature technology (SMR), while (peakload) electricity includes several relatively expensive renewable options like photovoltaics (the initial short-lasting surge in peakload electricity costs in the left panel of Fig. 6 originates from the introduction of such a technology, which subsequently benefits from cost decreases associated with (not explicitly modeled) processes like learning-by-doing and economies-of-scale).

Fig. 6 demonstrates that, as anticipated, fuel prices increase dramatically under climate change mitigation efforts, especially in the long term. In 2050 the price of fossil fuels is approximately $50 \%$ higher than in the baseline, while by 2100 the price ratio between the mitigation case and business-as-usual is approximately 10-15. The constraint on climate forcing yields a shadow price for emissions of $\mathrm{CO}_{2}$. This time-dependent price can be roughly interpreted as the emission penalty, or carbon tax, that would be required to reach the assigned climate target. The share of the $\mathrm{CO}_{2}$ tax in the total fossil fuel price increases over time, from about $10 \%$ in 2010 , to $15 \%$ in $2020,35-45 \%$ in 2050 and $75-90 \%$ in 2100 . Ethanol remains the cheapest fuel up to about 2050, given that for the relatively short run a good market exists for its use (as is the case in e.g. Brazil). After that, hydrogen proves to have the lowest price for the remainder of the century. Electricity is the second cheapest transport fuel by 2100 , but, as we will explain, does not widely penetrate as a result of the high purchase price of electricity-based (battery-equipped) vehicles.

\section{Discussion and alternative scenarios}

An unexpected outcome of our analysis is that electricity-based cars prove dominated by hydrogen-fueled vehicles. In contrast, the public discourse today seems to favor the former (see e.g. Göransson et al., 2010; Hedenus et al., 2010). Even while electric cars have the highest on-board efficiency of the modeled car types, under our optimization (cost minimization) framework and with the large range of technology options we model in order to simulate competitive conditions that are as realistic as possible, they are unable to penetrate the market and are ostentatiously out-shadowed by the widespread diffusion of hydrogen-based cars. The main reasons for this finding are threefold. First, if (as in our case) the carbon footprint is internalized in the fuel price (through the application of a global carbon tax to $\mathrm{CO}_{2}$ emissions of any origin), hydrogen proves in the longer run, from about 2050 onwards, the cheaper fuel in comparison to electricity. Second, hydrogen-based cars are assumed to cost significantly less than electric cars: on balance, the benefits that hydrogen-based vehicles possess in terms of fuel prices and upfront investment costs appear, in our modeling framework, to outweigh their drawback, in comparison to electric cars, with regards to efficiency. Third, particularly the long time frame of TIAM-ECN allows relatively easily for the construction of new costly infrastructures, as for hydrogen in our case, which turns out to become the optimal solution: in relative terms this long horizon downplays the benefit electric cars can draw today from existing power transmission and distribution systems (or path-dependency).

The fact that we only model the rudiments, not the details, of the option to establish a costly hydrogen infrastructure, needed for the large-scale transportation of hydrogen if it becomes a dominant energy carrier, at least in appearance does not seem to reverse the outcome of TIAM-ECN that favors the diffusion of hydrogen-fueled vehicles, which is demonstrated below. It is insightful to contrast our modeling outcome with perspectives from the innovation studies literature on the relative position of technologies in so-called "hype cycles" (e.g. Bakker et al., 2012). As views concerning the large-scale use of hydrogen were optimistic several years ago, the failure of the technology to deliver as quickly as hoped may have led to disillusionment and, correspondingly, low expectations for its future (even while government targets for e.g. fuel cells were sometimes met; see for instance DOE, 2011a, 2011b). Partly as a consequence, the electric car seems now to have replaced hydrogen fuel cell vehicles as the car technology of the future, towards which most hopes appear currently directed. The perhaps somewhat unexpected nature of the results reported in this article should thus also be seen in the light of the possibility that the present popular discourse may well inflate expectations for electricity based transportation (see e.g. Bakker, 2010 for a perspective on the blow-out of the hydrogen hype).

The outcome between diverging forces in the competitive playing field of the car industry will not only be determined by how costs and efficiencies for different vehicle technologies (as well as prices for different fuel types) are today, but also how these parameters will evolve over time. As for fuels, we observe no decisive distinction in our calculated price outcomes for different energy carrier types until about the middle of the century. During the second half of the century in our modeling exercise, however, electricity and hydrogen become the cheapest two transport fuels as a consequence of the increasing $\mathrm{CO}_{2}$ emission price. The price of hydrogen is still about 30\% lower in 2100 than that of electricity (which includes, in both cases, not only their production cost but also e.g. the cost associated with CCS activity or a $\mathrm{CO}_{2} \operatorname{tax}$ ). As for the other two parameters, a cost and efficiency gap between electric cars and (the two types of) hydrogen vehicles is assumed to persist throughout the century. Through technical progress, however, we assume that the upfront investment costs for both electricity- and hydrogen-based cars are reduced over time, that their efficiencies increase, and that the margin between them decreases during the time frame 2010-2050. For example, the hydrogen ICE hybrid car is assumed about 30\% cheaper than the electric car in 2010, while this difference is assumed to be reduced to approximately $20 \%$ in 2050. Inversely, in 2010 the energy required per $\mathrm{km}$ driven for the electric car is assumed some $60 \%$ lower than that for the hydrogen ICE hybrid vehicle, while this difference is reduced to $50 \%$ in 2050. Overall, under these assumptions, there appears sizeable benefit for the deployment of hydrogen-based vehicles, rather than electric cars.

Another element that plays an important role in determining the outcome of the relation between hydrogen and electricity as 
energy carriers in the transport sector is our assumption with respect to the discounting factor as applied to transportation. The relatively high discount rate (of 15\%/yr in Europe, and 30\% in the developing world) we use for levelizing the vehicle investments especially disadvantages those car types with high upfront purchase prices. Inversely, low discounting values would have mitigated the effect deriving from cost requirement differences, and would have yielded less accentuation of the dichotomy between electricity and hydrogen use in the car sector. Our high discounting assumptions, used to describe the investment priorities of individual consumers, contribute to explaining our finding that the electric car does not manage to penetrate the transport market. Similar arguments explain why plug-in hybrids are unable to diffuse in the market, as a result of a mix between cost, efficiency and carbon footprint factors. Our assumptions for the purchase prices and efficiencies of plug-in hybrid technology are similar to those for hydrogen fueled cars (both in 2010 and 2050), whereas in the long run the fuel they consume (gasoline or diesel versus hydrogen) differ in price by about a factor of two as a result of the simulated willingness-to-pay for internalizing climate change. Hence, the overall benefit falls to the latter.

Even while our results are internally consistent, uncertainties regarding future technology trends are so large that the development described in this paper can merely be considered as one possible scenario of how the transport sector might evolve. TIAMECN just allows for attempting to improve our understanding of the system dynamics between the use of fuels in different sectors under a range of different assumptions, rather in any way than predicting the future. In this light, it is especially insightful to generate alternative scenarios, which may be as likely as the base scenario presented in the previous section (that was entirely constructed on parameter values we found in the literature), to inspect the robustness of our results. We did this extensively, and report here a couple of our main findings. We tested our results by altering the cost assumptions regarding the two main classes of cars of our present interest, based on electricity and hydrogen as fuel types respectively, in order to see whether similar results are obtained. It proves that if across the century electric cars have 25\% lower investment cost requirements they may in 2100 , ceteris paribus, contribute by $12 \%$ to all car deployment (versus $85 \%$ for hydrogen vehicles). If electric cars show a 50\% reduction in investment costs during the century with respect to our reference case they may entirely take over the transport sector and make up nearly $100 \%$ of all car deployment in 2050 (and already close to a third by 2030).

Describing structures for which the spatial dimension is especially important is not a strength of a global spatially rather aggregated model. Refinement of the modeling of distribution infrastructures might well change our results. Currently both electric and hydrogen infrastructures are modeled in a simplified way, based on only a variable cost and transmission efficiency. Especially a hydrogen infrastructure would need significant upfront investments (given that currently only small hydrogen networks exist in a few countries), before it could allow a widespread penetration of hydrogen use in transportation. If the link between the diffusion of car technologies and required infrastructure developments was made more explicit, our results might change correspondingly (see e.g. Meyer and Winebrake, 2009). Addressing such an elaborate question would probably require another study, and likely with a model or through a methodology different than ours. Yet with TIAM-ECN we have run several other (and possibly as likely) scenarios with different stylized costs for the required hydrogen infrastructure, as proxy for the difficulty of materializing such an infrastructure. Since our model has perfect foresight and considers the full century while making its cost optimization, this proxy does not significantly differ from explicitly modeling detailed up-front infrastructure investments. If we increase the hydrogen transmission and distribution costs by almost an order of magnitude (from $2 \$ / G J$ to $15 \$ / G J$, the upper end of this range based on Yang and Ogden, 2007), the share of hydrogen cars in 2100 , ceteris paribus, is reduced from $95 \%$ down to $86 \%$, while the share of electric cars remains zero. Hence, we find that the possible error resulting from a misrepresentation of the costs associated with the establishment of a hydrogen transmission and distribution network is relatively modest. A significant increase of these network costs appears to have only a small impact on our findings. Of course, legal, social or political aspects may in real life be at least as relevant as economic arguments.

An interesting special case to inspect is what happens if not only our hydrogen infrastructure cost assumptions are subjected to change but simultaneously the assumed upfront investment costs for electric vehicles. It proves that a $25 \%$ purchase price reduction for electric cars is a tipping point. Under this cost reduction: (A) hydrogen cars disappear altogether in 2100 if hydrogen infrastructure costs are assumed to increase to $15 \$ / G J$, (B) they reach an approximate balance with electric cars if infrastructure costs are tripled to $6 \$ / G J$, while $(C)$ they continue to dominate the entire vehicle sector ( $87 \%$, versus $12 \%$ for electric cars) if infrastructure costs are kept at $2 \$ / G J$.

We performed a sensitivity test with regards to the stringency of the climate constraint. Stabilization of radiative forcing at levels below $3.0 \mathrm{~W} / \mathrm{m}^{2}$ is needed to maintain a relatively high probability to limit the global mean temperature increase to $2{ }^{\circ} \mathrm{C}$ (see e.g. van Vuuren et al., 2011). In the model version adopted for this research, however, TIAM-ECN is technically unable to reach the deep GHG emission reductions required to stay below such a low additional radiative forcing level. While in the meantime we have elaborated the simulation of energy technologies that allow the corresponding emission cuts, by including for example an expansive set of biomass options combined with CCS techniques that can materialize negative GHG emissions, for this paper we want to restrict ourselves to radiative forcing targets above $3.0 \mathrm{~W} / \mathrm{m}^{2}$, for reasons explained earlier. As depicted in Fig. 7, a reduction of the maximum allowed atmospheric radiative forcing from $4.0 \mathrm{~W} / \mathrm{m}^{2}$ down to $3.1 \mathrm{~W} / \mathrm{m}^{2}$ has a large effect on the types of cars introduced. The broad penetration of electricity in the transport sector, however, only kicks in after a large diffusion of hydrogen has been effectuated.

Fig. 7 also shows, for the European case, that a doubling of the costs of CCS would have an impact on the nature of car usage (see also Odenberger and Johnsson, 2010). Apart from a larger role reserved for the use of natural gas, however, the overall technology pattern remains relatively unaffected. More generally, an intimate link exists between the transport sector and CCS deployment, since the costs of CCS impact low-carbon production opportunities for both electricity and hydrogen. It is difficult to determine a priori the extent and nature of these impacts. While this may constitute a broad field for further investigation, we here perform a brief inspection of alternative scenarios. Suppose that the cost structure of CCS systems doubles, e.g. because envisaged cost reduction effects do not materialize (IPCC, 2005) or since $\mathrm{CO}_{2}$ storage is affected by leakage from the underground (van der Zwaan and Gerlagh, 2009; van der Zwaan and Smekens, 2009), where would one see the largest effect, in hydrogen-based or electricity-based transportation? Fig. 8 provides a preliminary answer, by pointing out that the overall level of CCS activity is somewhat reduced, but its structure of application remains largely unaffected. As can be seen from Fig. 8, CCS activity plays by far the largest role in electricity production, even when hydrogen (mostly produced through natural gas reforming with CCS) is the dominant fuel in the transport sector. This is another way of saying that the power sector contributes with a large (and increasing) share to overall energy supply. 
a
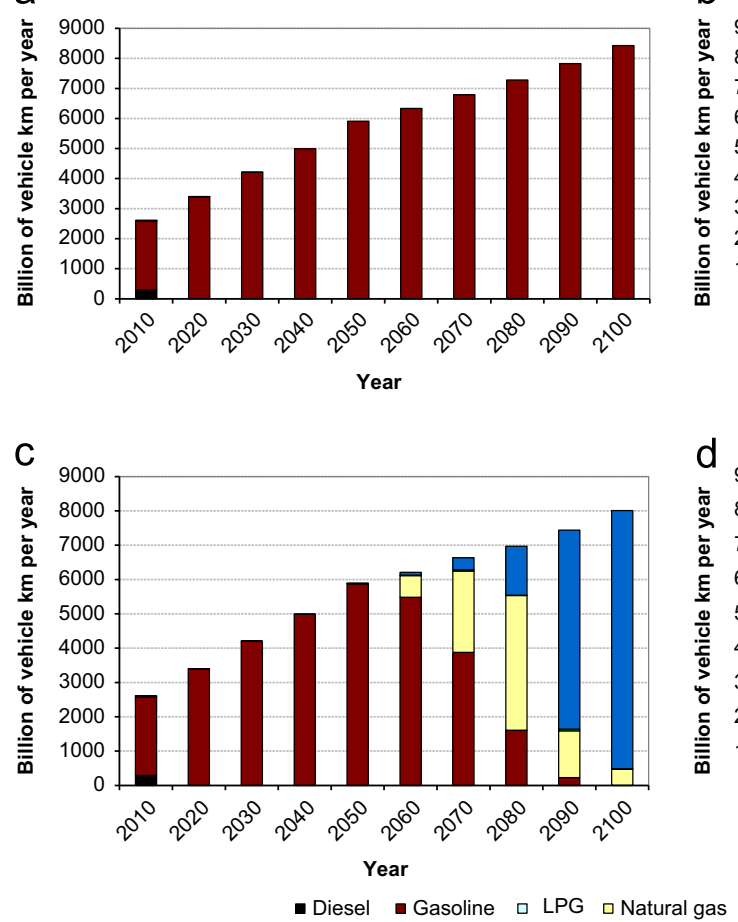

b

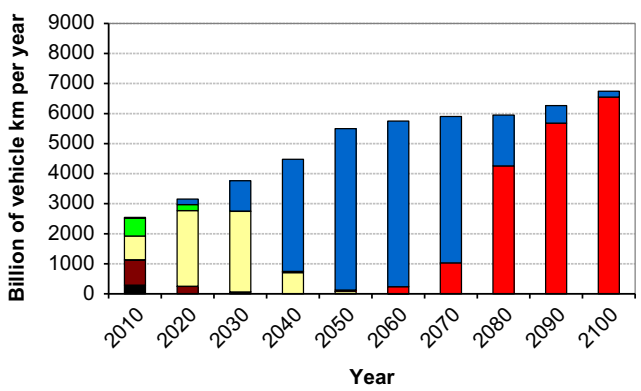

d

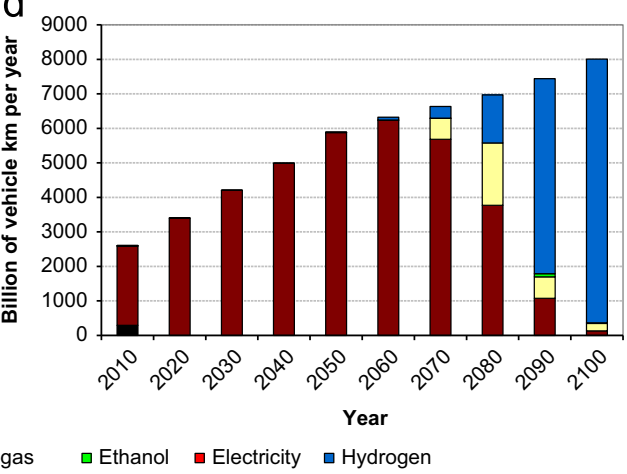

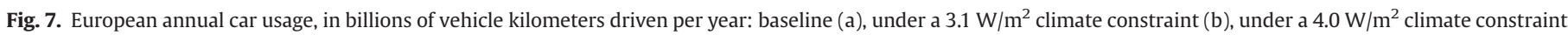
plus costly CCS (c), under a $4.0 \mathrm{~W} / \mathrm{m}^{2}$ climate constraint (d).
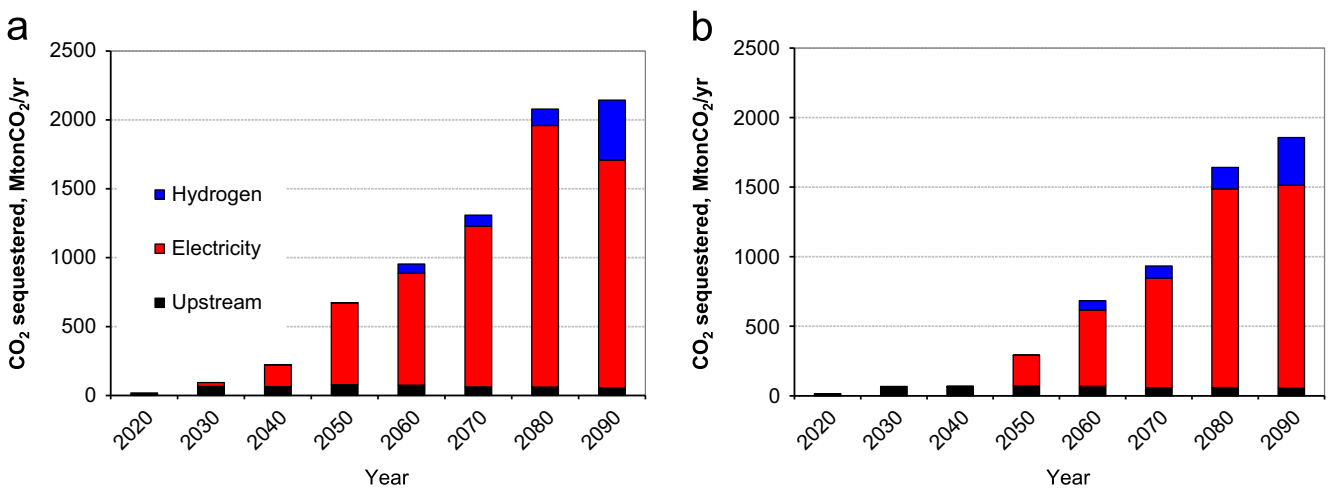

Fig. 8. The use of CCS in Europe across three different sectors under a $4.0 \mathrm{~W} / \mathrm{m}^{2}$ climate constraint (left panel) and the impact of a cost doubling for CCS (right panel).

While the use of TIAM-ECN may be able to shed light on a number of issues related to the nature of the transport sector of the future, a series of other questions must be left unanswered with this model and its underlying methodology. For example, Fig. 7(b) suggests that the transformation of the European fleet of passenger cars to hydrogen-based technology can be effectuated in about three decades, and similarly for battery-based technology. Micro-economic and/or market models are needed to assess the feasibility of such a transition in a time frame of approximately 30 years (as, for example, in Schäfer and Jacoby, 2006; Schäfer et al., 2009), complemented with analyses of consumer preferences, social behavior, socio-cognitive accumulation of expectations and a host of other factors that TIAM-ECN is unable to account for (see e.g. Bakker et al., 2012; Pol and Brunsting, 2011; Struben and Sterman, 2008).

Only rudimentarily reflected is the existence of a large diversity of potential storage alternatives that need to accompany many types of low-carbon (e.g. renewable) energy options, which TIAM-ECN models with relative paucity. Not considered in TIAM$\mathrm{ECN}$ is the possibility that for electricity-driven vehicles battery packs could eventually become part of the fuel and operation costs of a car, rather than remain component of its upfront investment costs, which could create more favorable economic dynamics for a broad adoption of the electric car in the transport sector. Another fundamental dimension not captured in TIAM$\mathrm{ECN}$ is a disaggregation of the transport sector in segments pertaining short, medium and long travel distances, which each may involve unique developments. We recognize this as a significant shortcoming that we may address by new modeling efforts in the future, but the impact of which we are unable to quantify until then. Similarly, information and communication technology will undoubtedly have a large role to play in transforming the current transportation system, for which other more dedicated research tools and models focusing merely on the transport sector exist or will need to be developed (see e.g. Greene and Plotkin, 2001; Greene and Duleep, 2008; Greene et al., 2008a; 2008b). Our modest contribution to the discussion is based on the more comprehensive approach of overall energy systems analysis, with transportation as one amongst other sectors. 


\section{Conclusion}

Through an analysis with the TIAM-ECN model we found that from a global overall energy systems perspective and under a unique $\mathrm{CO}_{2}$ price across all sectors and regions at every point in time, the decarbonization of the transport sector materializes later than that of other sectors such as power production. This is a modeling feature reflecting that GHG emission abatement is considered more expensive in transportation than for electricity generation. From the results of our stylistic model, however, one cannot derive the conclusion that in real life society's limited financial resources available for controlling climate change should be spent on abating $\mathrm{CO}_{2}$ emissions in the power sector first. We observe that, under the assumptions made, the use of hydrogen (initially mostly in internal combustion engines, but later predominantly in fuel cells) gradually becomes the dominant energy carrier in the transport sector. This outcome is in agreement with some recent publications (e.g. McKinsey, 2010), but is at loggerheads with current popular thought and policy analysis (IEA-ETP, 2010; IEA-WEO, 2010). Relatively high fuel and investment costs for battery electric vehicles, in comparison to those for hydrogen fuel cell cars, constitute the main reason for the lack of electric transportation in our scenario runs. The higher efficiency of electric cars appears, in our modeling framework, not to compensate for this difference. This conclusion, if justified, possesses important policy-relevant and commercial ramifications.

We also find that if the establishment of a hydrogen infrastructure proves exceedingly costly, or otherwise excessively intricate, electricity based transportation could broadly emerge this century but probably only if some requirements are fulfilled. For such a scenario, as we demonstrate, the costs of electric cars will probably need to go down significantly in order for them to play a meaningful role during the 21st century. For example, if in our model the electric car investment cost pattern remains as postulated in Table 2, accompanied by transmission and distribution costs of hydrogen increasing by almost an order of magnitude, electric vehicles will still not penetrate the car market. If, however, the electric car investment cost pattern is reduced by $25 \%$ (that is, a cost decrease of $25 \%$ across the century, including thus in 2010 and 2100), then a threefold increase in the hydrogen transmission and distribution costs could yield an electric car diffusion as large as that of hydrogen-based vehicles in 2100 , when each of these two car types would make up over $40 \%$ of the market. If the costs for electric vehicles are reduced by $50 \%$, they will fully overtake the transportation market, no matter how low the hydrogen infrastructure costs are. In real life, of course, all sorts of other and additional arguments other than economic optimality also apply: it could well be that electric cars become yet the predominant vehicle type if its current costs remain unaltered, simply for reasons of path dependency, or because of consumer preferences.

Whether hydrogen or electricity will predominate as energy carrier in the transport sector, or synthetic fuels such as based on biomass, different types of car technologies - and hybrid versions between them - are likely to develop and be deployed in tandem, depending for instance on regional energy resource availability. One of the possible explanations for why electric vehicles are today considered the supposed winner amongst multiple future transportation options is that they seem cheaper, since they match better the current infrastructure and therefore presumably require less guidance from government than the widespread use of hydrogen for fueling vehicles. We find that electric cars prove in most cases the more expensive option of the two in our long-term perspective. Whether our assumptions and findings are correct and sufficiently reflect how reality may materialize needs to be tested through further research complementary to our approach, e.g. through transportation-specific micro-economic modeling, psycho-sociological research, and detailed technology assessments of the costs of electric cars and the prices of their most critical component, batteries. It would therefore be useful to perform, amongst others, learning curve analysis applied to batteries, in the same way as recently undertaken for fuel cells (Schoots et al., 2010).

\section{Acknowledgments}

The analysis that allowed the publication of this paper was funded by the Pathways to Sustainable European Energy Systems project (at ECN registered under contract no. 600305). Some modeling and research contributions derived from work performed by the authors in the context of the PLANETS and ACTS projects (at ECN under contracts no. 77907 and no. 77910) funded by the European Commission (FP7/2007-2011, grant agreement no. 211859) and NWO (Netherlands Organisation for Scientific Research, ACTS Sustainable Hydrogen Programme, contract no. 053.61.024) respectively. Valuable input to this paper and the underlying analysis from Jos Bruggink, Marc Londo and Hilke Rösler is greatly acknowledged. The authors are particularly thankful for the detailed feedback received from two anonymous referees.

\section{References}

Anderson, K., Bows, A., 2008. Reframing the climate change challenge in light of post-2000 emission trends. Philosophical Transactions of the Royal Society A: Mathematical, Physical and Engineering Sciences 366 (1882), 3863-3882.

Bakker, S., 2010. The car industry and the blow-out of the hydrogen hype. Energy Policy 38 (11), 6540-6544.

Bakker, S., van Lente, H., Engels, R., 2012. Competition in a technological niche: the cars of the future. Technology Analysis \& Strategic Management 24 (5), 421-434.

Barreto, L., Makihira, A., Riahi, K., 2003. The hydrogen economy in the 21st century: a sustainable development scenario. International Journal of Hydrogen Energy 28 (3), 267-284.

Burke, A., H. Zhao, 2012. Energy Saving and Cost Projections for Advanced Hybrid, Battery Electric, and Fuel Cell Vehicles in 2015-2030, Research Report UCD-ITSRR-12-05, Institute for Transportation Studies, UC Davis, California.

Concawe, 2008. Well to Wheels Analysis of Future Automotive Fuels and Powertrains in the European Context, CONCAWE, EUCAR and JRC.

DOE, 2011a. Revised Portable Power Fuel Cell Targets, US Department of Energy, Hydrogen and Fuel Cells Program Record, Record \# 11009.

DOE, 2011b. Fuel Cell System Cost 2011, US Department of Energy, Hydrogen and Fuel Cells Program Record, Record \# 11012.

EC, 2011a, A Roadmap for moving to a competitive low carbon economy in 2050 Communication from the Commission to the European Parliament, the Council, the European Economic and Social Committee and the Committee of the Regions, COM(2011) 112, European Commission, Brussels, 8 March 2011.

EC, 2011b, Roadmap to a Single European Transport Area - Towards a Competitive and Resource Efficient Transport System. White Paper, COM(2011) 144, European Commission, Brussels, 28 March 2011.

EPA, 2010, Interim Joint Technical Assessment Report: Light-Duty Vehicle Greenhouse Gas Emission Standards and Corporate Average Fuel Economy Standards for Model Years 2017-2025, Office of Transportation and Air Quality, US Environmental Protection Agency, US Department of Transportation, California Environmental Protection Agency.

Forest, C.E., Stone, P.H., Sokolov, A., Allen, M.R., Webster, M.D., 2002. Quantifying uncertainties in climate system properties with the use of recent climate observations. Science 295 (5552), 113-117.

GEA, 2012. Global Energy Assessment. Cambridge University Press, IIASA (Laxenburg, Austria).

Gerlagh, R., van der Zwaan, B.C.C., 2006. Options and Instruments for a deep cut in $\mathrm{CO}_{2}$ emissions: carbon dioxide capture or renewables, taxes or subsidies? The Energy Journal 27 (3), 25-48.

Gerlagh, R., van der Zwaan, B.C.C., 2012. Evaluating uncertain $\mathrm{CO}_{2}$ abatement over the very long term. Environmental Modeling and Assessment 17 (1/2), 137-148.

Göransson, L., Karlsson, S., Johnsson, F, 2010. Integration of plug-in hybrid electric vehicles in a regional wind-thermal power system. Energy Policy 38, 5482-5492.

Grahn, M., 2009. Cost-effective Fuel and Technology Choices in the Transportation Sector in a future Carbon Constrained World, Ph.D. thesis, Chalmers University, Sweden. 
Greene, D.L., Duleep, K.G., 2008. Bootstrapping a Sustainable North American PEM Fuel Cell Industry: Could a Federal Acquisition Program Make a Difference? ORNL/TM-2008/183. Oak Ridge National Laboratory, Oak Ridge, Tennessee.

Greene, D.L., Plotkin, S.E., 2001. Energy futures for the US transport sector. Energy Policy 29, 1255-1270.

Greene, D.L., German, J., Delucchi, M.A., 2008a. Fuel economy: the case for market failure. In: Sperling, D., Cannon, J.S. (Eds.), Reducing Climate Impacts of the Transportation Sector. Springer Science+Business Media 〈springer.com〉.

Greene, D.L., Leiby, P.N., James, B., Perez, J., Melendez, M., Milbrandt, A., Unnasch, S. Hooks, M., 2008b. Analysis of the transition to hydrogen fuel cell vehicles \& the potential hydrogen energy infrastructure requirements, ORNL/TM-2008/30. In McQueen, S. (Ed.), Oak Ridge National Laboratory, Oak Ridge, Tennessee, directed by S. Gronich.

Grübler, A., Energy transitions research: insights and cautionary tales. Energy Policy $50,2012,8-16$

Gül, T., 2008. An Energy-Economic Scenario Analysis of Alternative Fuels for Transport. Ph.D. Thesis No. 17888, ETH Zürich, Switzerland.

Hedenus, F., Karlsson, S., Azar, C., Sprei, F., 2010. Cost-effective energy carriers for transport - the role of the energy supply system in a carbon-constrained world. International Journal of Hydrogen Energy 35, 4638-4651.

Höhne, N., Taylor, C., Elias, R., Den Elzen, M., Riahi, K., Chen, C., Rogelj, J., Grassi, G., Wagner, F., Levin, K., Massetti, E., Xiusheng, Z., 2012. National GHG emissions reduction pledges and $2{ }^{\circ} \mathrm{C}$ : Comparison of studies. Climate Policy 12 (3) 356-377.

IEA, 2009. Transport, Energy and $\mathrm{CO}_{2}$ : Moving Toward Sustainability. Internationa Energy Agency, Paris.

IEA-ETP, 2010. International Energy Agency (IEA). OECD, Energy Technology Perspectives (ETP), Paris, France.

IEA-ETP, 2012. International Energy Agency (IEA). OECD, Energy Technology Perspectives (ETP), Paris, France.

IEA-WEO, 2010. International Energy Agency (IEA). OECD, World Energy Outlook (WEO), Paris, France.

IPCC, 2005. Special Report on Carbon Dioxide Capture and Storage, Working Group III, Intergovernmental Panel on Climate Change. Cambridge University Press.

IPCC, 2007, Climate Change 2007: Synthesis Report, Working Groups I, II and III, Fourth Assessment Report, Intergovernmental Panel on Climate Change, Geneva, Switzerland.

Johnsson, F. (Ed.), Chalmers University.

Johnsson, F., 2011b. Perspectives on $\mathrm{CO}_{2}$ capture and storage. Greenhouse Gases Science and Technology 1, 1-15.

Keppo, I. and B.C.C. van der Zwaan, The impact of uncertainty in forcing targets and $\mathrm{CO}_{2}$ storage availability on long-term climate change mitigation. Environmental Modelling and Assessment 2012, 17(1): 177-191.

Lackner, K.S., Brennan, S.A., Matter, J. Park, A.-H.A., Wright, A., van der Zwaan, B.C. C., 2012. The urgency of the development of $\mathrm{CO}_{2}$ capture from ambient air Proceedings of the National Academy of Sciences 109 (33), 13156-13162, August 14.

Loulou, R, 2008. ETSAP-TIAM: the TIMES integrated assessment model, Part II: mathematical formulation. Computational Management Science 5 (1-2), 41-66.

Loulou, R., Labriet, M., 2008. ETSAP-TIAM: the TIMES integrated assessment model, Part I: model structure. Computational Management Science 5 (1-2), 7-40.

McCollum, D., Yang, C., Yeh, S., Ogden, J., 2012. Deep greenhouse gas reduction scenarios for California-strategic implications from the CA-TIMES energyeconomic systems model. Energy Strategy Reviews 1, 19-32.

McKinsey, 2010, The role of battery electric vehicles, Plug-in Hybrids and Fuel Cell Electric Vehicles. Available from http://ec.europa.eu/research/fch/pdf/a_portfo lio_of_power_trains_for_europe_a_fact_based_analysis.pdf.

Meyer, P.E., Winebrake, J.J., 2009. Modeling technology diffusion of complementary goods: the case of hydrogen vehicles and refueling infrastructure. Technovation 29, 77-91.

Nakicenovic, N., 1986. The automobile road to technological change: diffusion of the automobile as a process of technological substitution. Technologica Forecasting and Social Change 29 (4), 309-340.
O'Neill, B.C., Riahi, K., Keppo, I., 2010. Mitigation implications of midcentury targets that preserve long-term climate policy options. Proceedings of the National Academy of Sciences, USA 107 (3), 1011-1016.

Odenberger, M., Johnsson, F., 2010. Pathways for the European electricity supply system to 2050 - the role of CCS to meet stringent $\mathrm{CO}_{2}$ reduction targets. International Journal of Greenhouse Gas Control 4, 327-340.

Pacala, S., Socolow, R., 2004. Stabilization wedges: solving the climate problem for the next 50 years with current technologies. Science 305, 968-972.

Plotkin, S., Stephens, T., McManus, W., 2013. Vehicle Technology Deployment Pathways: An Examination of Timing and Investment Constraints, Transportation Energy Futures Report Series, Prepared for the U.S. Department of Energy by Argonne National Laboratory, Argonne, IL, DOE/GO-102013-3708.

Pol, M., S. Brunsting, 2011, Car Owners' Perceptions and Attitudes on Innovative Vehicles. Energy research Centre of the Netherlands, Report ECN-E-11-068.

Rivera-Tinoco, R., Schoots, K., van der Zwaan, B.C.C., 2012. Learning curves for solid oxide fuel cells. Energy Conversion and Management 57, 86-96.

Rösler, H., J.J.C. Bruggink and I.J. Keppo, 2011, Design of a European sustainable hydrogen model: model structure and data sources, ECN-E-11-041, available at 〈www.ecn.nl $\rangle$, August 2011, Petten, The Netherlands.

Rösler, H., B.C.C. van der Zwaan, I.J. Keppo, J.J.C. Bruggink, 2013.Two Types of Transportation: Electricity versus Hydrogen under Stringent Climate Change Control, mimeo.

Schäfer, A., Jacoby, H.D., 2006. Vehicle technology dynamics under $\mathrm{CO}_{2}$-constraint: a general equilibrium analysis. Energy Policy 34 (9), 975-985.

Schäfer, A., Heywood, J.B., Jacoby, H.D., Waitz, I.A., 2009. Transportation in a Climate-Constrained World. MIT Press.

Schoots, K., Kramer, G.J., van der Zwaan, B.C.C., 2010. Technology learning for fuel cells: an assessment of past and potential cost reductions. Energy Policy 38, 2887-2897.

Sperling, D., Lutsey, N., 2009. Energy Efficiency in Passenger Transportation. National Academy of Engineering, USA, The Bridge p. 39 2, June.

Struben, J., Sterman, J.D., 2008. Transition challenges for alternative fuel vehicle and transportation systems. Environment and Planning B: Planning and Design 35, 1070-1097.

Syri, S., Lehtilä, A., Ekholm, T., Savolainen, I., Holttinen, H., Peltola, E., 2008. Global energy and emissions scenarios for effective climate change mitigationdeterministic and stochastic scenarios with the TIAM model. International Journal of Greenhouse Gas Control 2 (2), 274-285.

Taylor, M.R., Rubin, E.S., Hounshell, D.A., 2005. Regulation as the mother of innovation: the case of $\mathrm{SO}_{2}$ control. Law \& Policy 27 (2), 348-378.

Uyterlinde, M.A., C.B. Hanschke, P. Kroon, 2005, Duurzame innovatie in het wegverkeer. Een evaluatie van vier transitiepaden voor het thema Duurzame Mobiliteit, Report ECN-E-08-076, Energy research Centre of the Netherlands, Petten.

Victor, D., 2009. Global warming: why the $2{ }^{\circ} \mathrm{C}$ goal is a political delusion. Nature 459 (7249), 909.

van Vuuren, D.P., Stehfest, E., den Elzen, M.G.J., Kram, T., van Vliet, J., Deetman, S. Isaac, M., Klein Goldewijk, K., Hof, A., Mendoza Beltran, A., Oostenrijk, R., van Ruijven, B., 2011. RCP2.6: exploring the possibility to keep global mean temperature change below $2^{\circ} \mathrm{C}$. Climatic Change 109, 95-116.

Yang, C., Ogden, J., 2007. Determining the lowest-cost hydrogen delivery mode. International Journal of Hydrogen Energy 32 (2), 268-286.

Yeh, S., McCollum, D., 2011. Optimizing the transportation climate mitigation wedge. In: Ogden, J., Anderson, L. (Eds.), Sustainable Transportation Energy Pathways. Institute for Transportation Studies, UC Davis, California, Chapter10.

van der Zwaan, B.C.C., Gerlagh, R., 2009. Economics of geological $\mathrm{CO}_{2}$ storage and leakage. Climatic Change 93 (3/4), 285-309.

van der Zwaan, B.C.C., Smekens, K., 2009. $\mathrm{CO}_{2}$ capture and storage with leakage in an energy-climate model. Environmental Modeling and Assessment 14 (2), $135-148$.

van der Zwaan, B.C.C., Schoots, K., Rivera-Tinoco, R., Verbong, G.P.J., 2011. The cost of pipelining climate change mitigation: an overview of the economics of $\mathrm{CH}_{4}$, $\mathrm{CO}_{2}$ and $\mathrm{H}_{2}$ transportation. Applied Energy 8, 3821-3831. 